\title{
Automatic Motion Control System of Roundness Testing Machine
}

\author{
Athiyya Rieke Hisana* \\ Dept. of Mechanical Engineering \\ Universitas Riau \\ Pekanbaru, Indonesia \\ athiyyah.rieke2370@student.unri.ac.id
}

\author{
Dodi Sofyan Arief \\ Dept. of Mechanical Engineering \\ Universitas Riau \\ Pekanbaru, Indonesia \\ dodidarul@yahoo.com
}

*Corresponding author: athiyyah rieke hisana, athiyyah.rieke2370@student.unri.ac.id

\begin{abstract}
Roundness has an important role in terms of dividing the load equally, determining component life, determining adjustment conditions, determining rotation accuracy, and facilitating lubrication. To measure the roundness required a tool that can perform measurements with precision. With a roundness measuring instrument that has an automatic motion control system it will be able to produce more efficient data retrieval and higher accuracy than previous research. The control system in this tool is a system that regulates the automatic movement of the roundness gauge. Where the function of this automatic motion control system is to measure the test object using a chuck as a clamp, the indicator dial is directed by the $X$ and $Y$ axes to the data collection point on the test object which is connected to the driving motor. Axis $Y$ moves in translation to direct the indicator dial on the "arm" to the pick-up point which moves automatically depending on the selected data collection mode, then the indicator dial starts taking measurement data until the measurement data retrieval is complete, then the motor moves from top to bottom, to perform reversible data retrieval. Stepper motor on the chuck will also move. There are $\mathbf{2}$ modes in this machine, it is mode $\mathbf{1}$, where the resulting data is in the form of a "ring" and for mode 2 , the resulting data is "spiral". It was found that the translational speed of the screw shaft in the vertical movement is $0.025 \mathrm{~m} / \mathrm{s}$ and the horizontal linear speed is $0.026 \mathrm{~m} / \mathrm{s}$.
\end{abstract}

Keywords-control system, motor stepper, roundness testing machine.

\section{INTRODUCTION}

Measurement is comparing a quantity with a reference or comparison or reference quantity. Measurement is an activity aimed at identifying the size of an object or symptom. Measurements can be carried out in two ways, namely:

1. Using standard tools

2. Using non-standard tools

Roundness is the uniformity of the distance between the center point and the outermost point (radius). Roundness measurement is a measurement to check the roundness of an object, or in other words to find out whether an object is really round or not, when viewed carefully with a measuring instrument.. Roundness can be measured in a simple way using the Dial Indicator, but currently it is still difficult to determine the roundness so we need a program that can analyze directly. Method to know the accuracy of the measuring instrument and the measurement results, of course there must be a basic reference that is used as a clear reference for the source. Mandrel is a standard measuring object that has been calibrated and certified for its roundness quality by a data calibration agency. Mandrel will be used in this research as a basic reference to determine the accuracy of making roundness applications. The Roundness Tester Machine is a measuring tool using a mini chuck as a grip for the workpiece to be measured, and is equipped with a workpiece driving motor and $\mathrm{X}$ and $\mathrm{Y}$ axis arm drive, then the measurement data from this tool can be input and processed directly to the computer using the Microsoft Excel program, but this tool has not been tested for the accuracy of the measurement or the accuracy of the measurement results and there is a need for research that discusses studies or efforts made to standardize and determine the accuracy or accuracy and the amount of deviation from the measurement results on the Roundness Tester Machine.

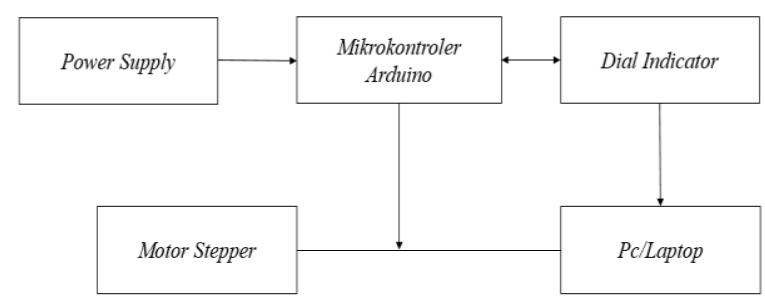

Fig. 1. Diagram Of Working Mechanism the Roundness Testing Machine 


\section{Methodology}

In this research, Roundness testing machine is specially designed to capable of continuous form measurement (some of data points around the circumference of part), giving you ability to thoroughly map the part's form and to measure whether a workpiece is perfectly round or not. This roundness testing machine have 2 methods testing so that resulting in more varied.

a. Object research

A mandrel is a standard measuring instrument that has been calibrated and certified for roundness quality by a calibration institution, namely PT. Global Quality Indonesia, this data will be used as a basic reference to determine the accuracy of making roundness applications.

b. Tools research



Fig. 2. Roundness Testing Machine

Dial Indicator, used to measure roundness.

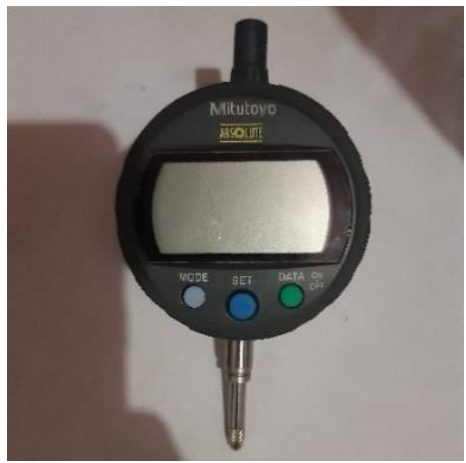

Fig. 3. Dial Indicator

Microcontroller Arduino Mega 2560, Arduino mega 2560 used as a "brain" to save the programs.

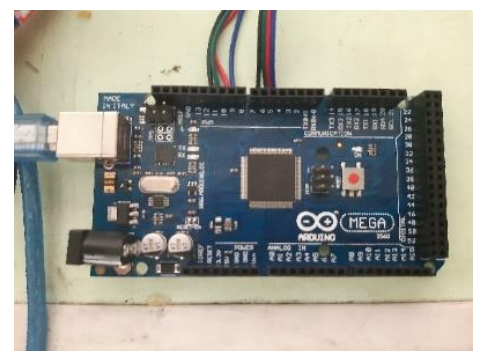

Fig. 4. ArduinoMega256

Laptop used as to operate program.

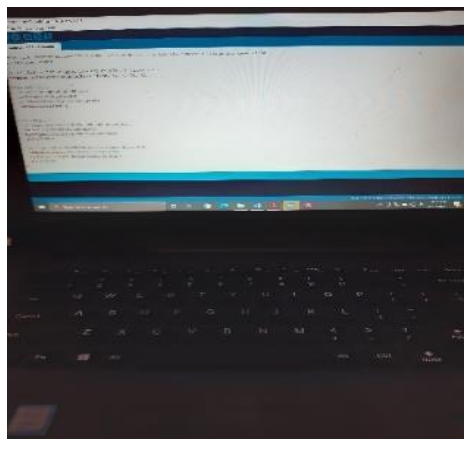

Fig. 5. Laptop

Limit switch is used as a limit of axis- $\mathrm{X}$ and axis- $\mathrm{Y}$ movement.

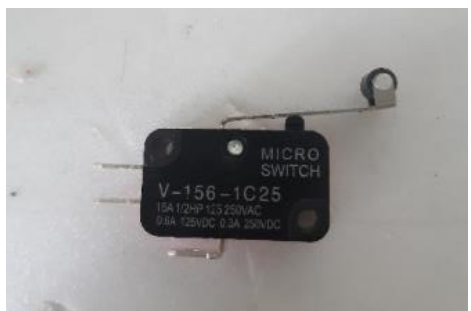

Fig. 6. Limit switch

Stepper Motor, there are 3 stepper motors, in axis- $\mathrm{X}$, axis- $\mathrm{Y}$ and rotate the Chuck.

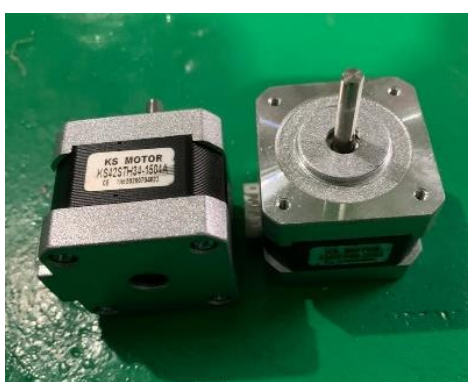

Fig. 7. stepper motor

Power Supply, to supply electric current to components

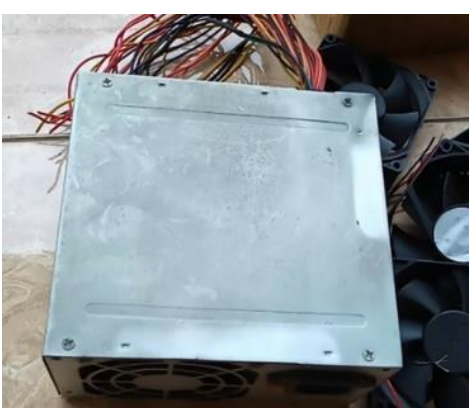

Fig. 8. Power Supply

The Adapter input block supplies a voltage to the Arduino and give 5 volts then the Arduino share the voltage into the Shield L298N driver motor and stepper motor. The motor driver can be adjusted according to needs, which requires enough thrust to drive the chuck and $\mathrm{Y}$-axis to the position adjusted by the operator, so that the stepper motor used has the power according to the needs to the roundness testing machine 


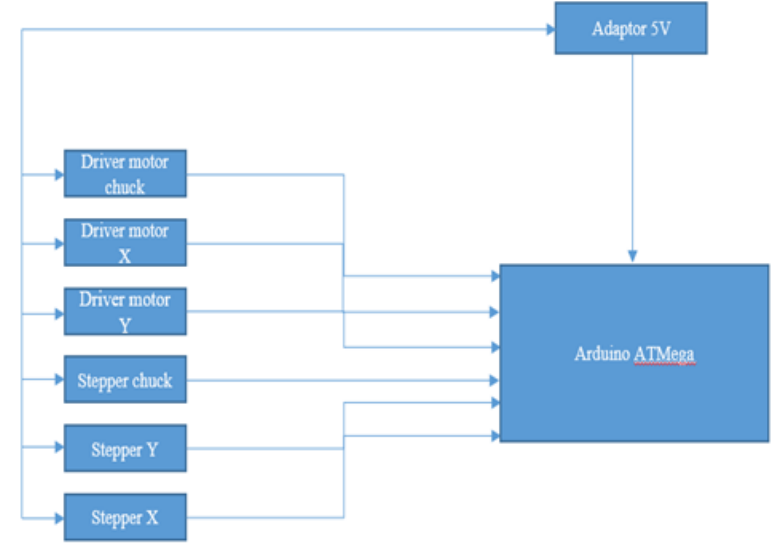

Fig. 9. Control system block diagram

Based on the diagram, the function of each block can be described:

a. Arduino Mega 2560

Arduino as the brain of the system, input data from users and motors is processed by a microcontroller whose output will be fed to the motor driver and stepper motor.

b. Motor Shield L298N

Motor Shield L298N in this circuit had a function as a motor driver to command the motor to move.

c. Stepper Motor X-axis

The position of the motor moves from left to right with the coordinate point of 0.0 (horizontal).

d. Stepper Motor Y-axis

The position of the motor moves up and down with the coordinate point of 0.0 (vertical).

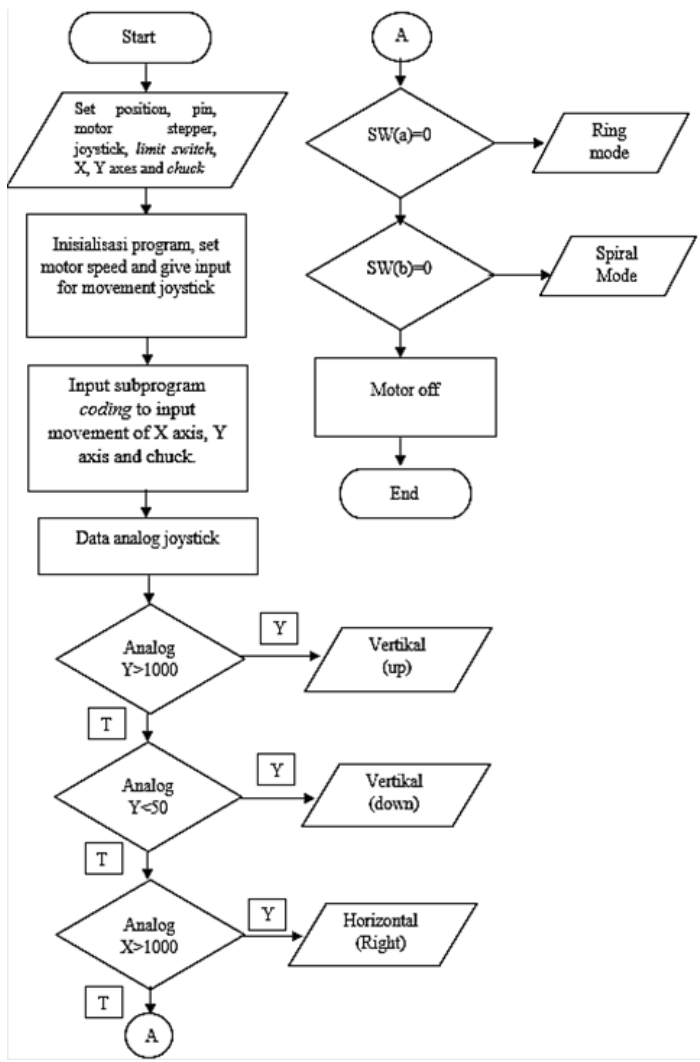

The flowchart of roundness testing control system performance is designed as illustrated in the system flowchart shown in Figure 3. on the input section there is a set of pin positions that will be installed on the Arduino Mega2560 microcontroller, for electronic components such as stepper motors for the $\mathrm{X}$ axis, $\mathrm{Y}$ axis and motors to rotate the chuck that will clamp the test object, limit switches used to limit the movement of the $\mathrm{X}$ axis and $\mathrm{Y}$ axis., and a joystick that is used to control the direction of movement of the two axes manually. Then in the output or process section, the program is initialized by setting the desired speed for each motor and providing a joystick input notification. Then enter the subprogram where there is a division of functions that support the movement of the roundness measuring instrument, which provides the function of horizontal movement of the $\mathrm{X}$ axis, vertical movement of the $\mathrm{Y}$ axis, and chuck rotation. When Switch (Y) moves greater than 1000 then the movement is vertical upwards, if less than 50 then the movement is vertical downwards. When the switch (X) moves greater than 1000 then the movement is horizontal to the right and if the joystick moves less than 50 then the horizontal movement is to the left.

\section{RESULT AND DISCUSSION}

The explanation of the Arduino source code on the roundness measuring instrument as follows:

1. Definition of libraries, constants and variables

In this section, we define and declare the libraries and variables used during the testing process. The library used is "stepper's" which functions to drive the stepper motor in the chuck component, X-axis and Y-axis. In this section also defined the vertical drive movement and pin content on each component connected to the Arduino.

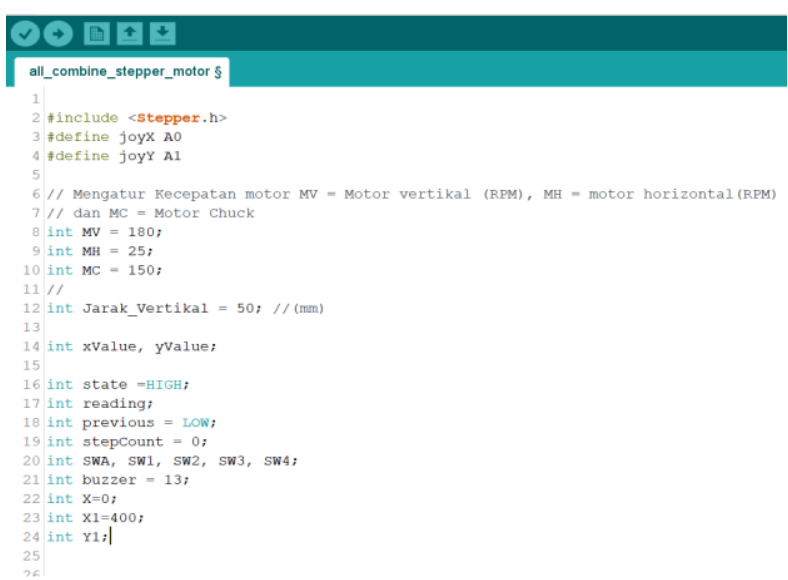

Fig. 11. Library in Arduino IDE

2. Setup

In this section, stepper initiation is carried out. Stepper 1 will move the $\mathrm{X}$ axis, stepper 2 for the $\mathrm{Y}$ axis and stepper motor 3 contained in the chuck will set the chuck rotation speed so that it is not too slow or not too fast or depends on the desired speed, the setup is also set how much distance increases at each point For take data, how many

Fig. 10. Flowchart of control system program 
times do you want to record data, then the baud rate for serial is set to 9600 .

3. Loop (Main)

In this section, a process input joystick to the $\mathrm{X}$-axis movement and the $\mathrm{Y}$-axis, analog switches that will be used as a reset button. Then this joystick movement is interpreted into horizontal (right, left) and vertical (up, down) works manually.

4. Subprogram

In this section, there are several functions that support the motion system process on the tool. There are 2 functions used for the movement process, that is:

\section{a. Execution Function}

This function, interpreting the instructions on the movement coding inputted into Arduino ide into a movement that horizontal $\mathrm{X}$-axis movement and vertical $\mathrm{Y}$-axis movement and movement of chuck used to clamp the test object. In this function is performed buzzer setting process and limit switches.

b. Test Function

In this function, a process of inputting types of testing methods of data, there are two modes of data collection that is mode 1 is a test mode in which the data results roundness obtained a form of "ring" For the next test methods, methods 2 , where the test data results obtained are in the form of a "spiral", the testing process with the chuck and the $\mathrm{Y}$ axis moves together at different speeds so as to produce spiral-shaped test data.

In the spiral method, the stepper motor in the chuck rotates according to the specified speed (the program uses a speed of $120 \mathrm{rpm}$ ) and the motor on the $\mathrm{Y}$ axis also moves according to the chuck.

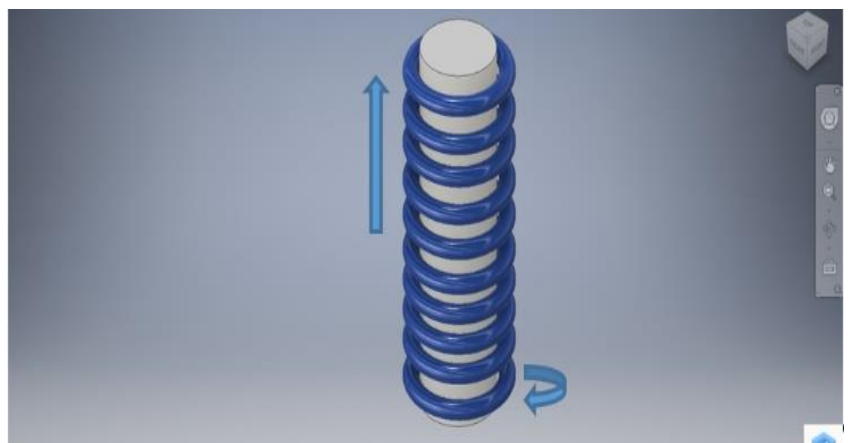

Fig. 12. Method 1-ring method

When record data with the ring method of record data process is with the stepper motor on the chuck rotating at a regulated speed of $75 \mathrm{rpm}$, but the position of the $\mathrm{Y}$ axis does not move. After taking data at the first point, then the $\mathrm{Y}$ axis moves up in into $10 \mathrm{~mm}$ or according to how much distance users want.

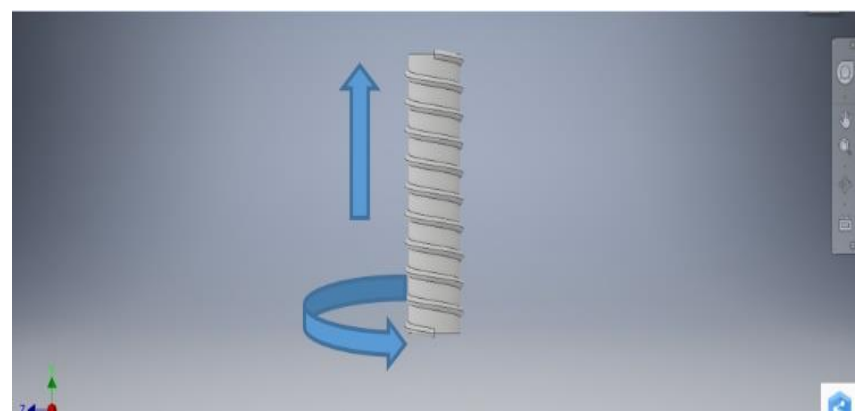

Fig. 13. Method 2-Spiral

TABLE I. Navigation tools results

\begin{tabular}{|c|c|c|}
\hline Button & direction of use & $\begin{array}{c}\text { Axis } \\
\text { movement }\end{array}$ \\
\hline Analog 1 & forward & Y axis (Up) \\
\hline Analog 1 & Backward & Y axis (down) \\
\hline Analog 1 & To the right & X axis(right) \\
\hline Analog 1 & To the left & X axis(left) \\
\hline
\end{tabular}

On the $\mathrm{Y}$ axis there is a calculation of the translation speed on the screw shaft, because the type of linear guide used in this study is a screw shaft. The speed set in the program for vertical is $150 \mathrm{rpm}$, the speed of the Y stepper motor can be adjusted as desired. The results of the translational speed obtained when the motor rotation speed of $150 \mathrm{rpm}$ is:

$$
150 \frac{\text { ratio }}{\text { menit }}=150 \frac{\mathrm{cm}}{\text { menit }}=1,5 \frac{\mathrm{m}}{60 \mathrm{~s}}=0,025 \mathrm{~m} / \mathrm{s}
$$

It is found the translational speed that occurs in the screw shaft is $0.016 \mathrm{~m} / \mathrm{s}$. Meanwhile, the linear velocity on the horizontal is:

$$
\text { Vlinear }=\frac{\pi \times d \times 10}{60 s}=\frac{\pi \times 0,02 \mathrm{~m} \times 25}{60 \mathrm{~s}}=0,026 \mathrm{~m} / \mathrm{s}
$$

This test is done by doing a demo on the tool 5 times upward movement in mode 1 or ring mode and 5 times upward movement in mode 2 or spiral mode. This method uses a millimeter block paper that will be attached to the mandrel, then attach the pen to the dial indicator arm and the millimeter paper results are measured and compared with the data in the input program. This actual test is carried out to find out how the standard deviation value for the accuracy of the tool is.

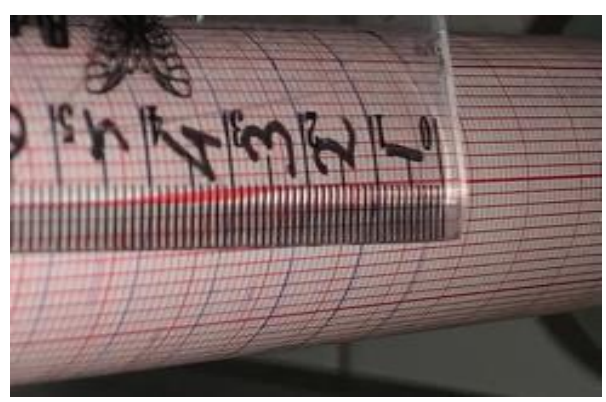

Fig. 14. Testing process-Ring method

It can be seen in the final image for the distance in each circle increment for mode 1 or ring mode. 


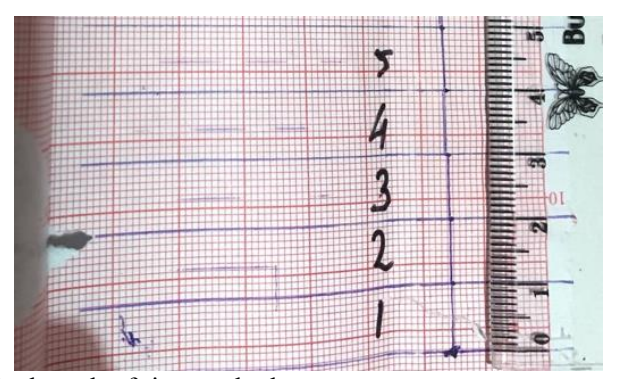

Fig. 15. Final result of ring method

Then after taking or testing the repeatability of the data, the following results are:

TABLE II. Data Accuracy Testing Tool Mode 1

\begin{tabular}{rcccc}
\hline No & $\begin{array}{c}\text { Distance each } \\
\text { other/output } \\
(\mathrm{x})\end{array}$ & Input & $\begin{array}{c}\text { deviation } \\
\left(\mathrm{x}_{\mathrm{i}}\right)\end{array}$ & $\left(\mathrm{x}_{\mathrm{i}}-\bar{x}\right)^{2}$ \\
$(\mathrm{~mm})$ & $(\mathrm{mm})$ & $(\mathrm{mm})$ & $(\mathrm{mm})$ \\
\hline 1 & 10 & 10 & 0 & 0 \\
2 & 10 & 10 & 0 & 0 \\
3 & 10 & 10 & 0 & 0 \\
4 & 10 & 10 & 0 & 0 \\
5 & 10 & 10 & 0 & 0 \\
\hline Mean & 10 & 10 & 0 & 0 \\
Total & 50 & 50 & 0 & 0 \\
\hline
\end{tabular}

The results of data processing are known, calculations can be made to find the standard deviation of the test for mode 1 is:

$$
\sqrt{\sum_{i=1}^{n} \frac{(x i-\bar{x})^{2}}{n-1}}=\sqrt{\frac{0}{5-1}}=0
$$

The process of testing the accuracy of the automatic motion program of the roundness measuring instrument for mode 2 can be seen in the following figure,

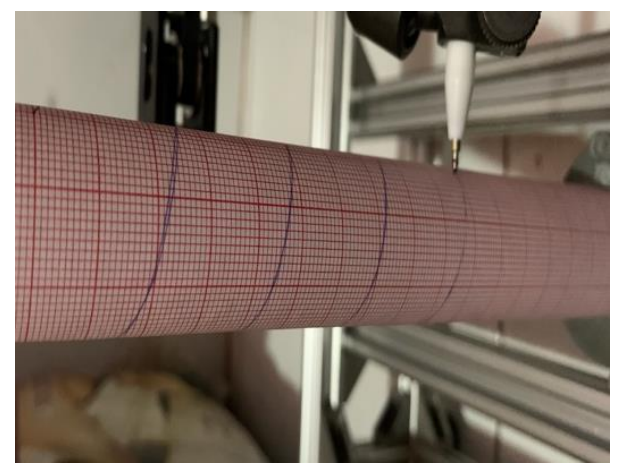

Fig. 16 Testing Process-Spiral mode

It can be seen in the final image for the distance in each circle increment for mode 2 or spiral mode. Then after taking or testing the repeatability of the data, the following next results.

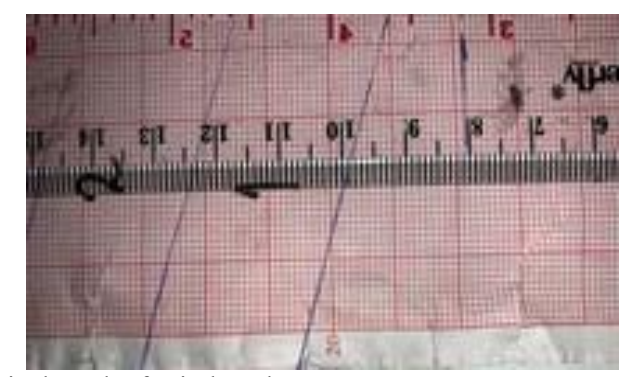

Fig. 17. Final result of spiral mode

TABLE III. Data Accuracy Testing Tool Mode 2

\begin{tabular}{ccccc}
\hline No & $\begin{array}{c}\text { Distance each } \\
\text { other/output } \\
(\mathrm{x}) \\
(\mathrm{mm})\end{array}$ & Input & $\begin{array}{c}\text { deviation } \\
\left(\mathrm{x}_{\mathrm{i}}\right)\end{array}$ & $\left(\mathrm{x}_{\mathrm{i}}-\bar{x}\right)^{2}$ \\
\hline 1 & 25 & 25 & $(\mathrm{~mm})$ & $(\mathrm{mm})$ \\
2 & 25 & 25 & 0 & 0 \\
3 & 25 & 25 & 0 & 0 \\
4 & 25 & 25 & 0 & 0 \\
5 & 25 & 25 & 0 & 0 \\
\hline Mean & 25 & 25 & 0 & 0 \\
Total & 125 & 125 & 0 & 0 \\
\hline
\end{tabular}

The results of data processing are known, calculations can be made to find the standard deviation of the test for mode 2 is:

$$
\sqrt{\sum_{i=1}^{n} \frac{(x i-\bar{x})^{2}}{n-1}}=\sqrt{\frac{0}{5-1}}=0
$$

After doing these tests, it can be analyzed that the input contained in the program then produces output on the machine that has a consistent according to what was inputted. It can be concluded that this machine has a good accuracy.

\section{CONCLUSIONS}

As for the conclusion of the design and manufacture of a control system automatic motion for roundness testing machine are: 1) A schematic design of a control system has been obtained using the ArduinoMega2560 microcontroller for a roundness measuring instrument capable of moving in the $\mathrm{X}$-axis, $\mathrm{Y}$-axis and the rotation of the chuck clamping the test object. 2) This roundness meter has a motor speed program that can be adjusted, namely the chuck, $\mathrm{X}$ axis and $\mathrm{Y}$ axis. With a speed of $150 \mathrm{rpm}$, the translational speed of the vertical movement is $0.025 \mathrm{~m} / \mathrm{s}$ and the horizontal linear speed is $0.026 \mathrm{~m} / \mathrm{s}$. 3) This roundness measuring instrument has two data retrieval methods, namely method 1 with ringdata collection with a distance of each point $10 \mathrm{~mm}$ and method 2 with spiral data collection and there is no difference between the input in the program and the result in the output. 


\section{ACKNOWLEDGMENT}

The authors gratefully thanks to God and would like to convey a great appreciation to Riau University, Indonesia for supporting this research.

\section{REFERENCES}

[1] Arief, D. S., Shiddiq, M., Prayitno, A., Badri, M., Nugraha, A. S., \& Muflihana, A, "Calibration of $40 \mathrm{Kg}$ Capacity Digital Scale on Automatic Machine Measurement Mass and Dimension Based on Arduino Uno Using CSIRO-NML: 1995 Method", Proceeding of Ocean, Mechanical and Aerospace-Science and Engineering-, 5(1), 97 102, 2018.

[2] Prayitno, A., Arief, D. S., Shiddiq, M., Al Ihsan, R., \& Tarmizan, H, "Automatic Control System on the Machine Vision Volume and Weight Gauges", Proceeding of Ocean, Mechanical and Aerospace-Science and Engineering-, 5(1), 92-96, 2018.

[3] Arief, D.S., Jadmiko, Eko, Prayitno, A., Badri, Muftil., \& Dalil, M, "Making roundness measurement applications and control systems on the Roundness Testing Machine", Journal of Ocean, Mechanical and Aerospace-science and engineering-, 63(3), 17-21, 2018.

[4] Majid, M, "Implementasi Arduino Mega 2560 Untuk Kontrol Miniatur Elevator Barang Otomatis", 2016.
[5] Nugroho, E. C, Prototipe Mesin CNC 2D Berbasis Arduino Uno, 25(1), 2019.

[6] Widodo, D. S., Sembodo, A., Mukmin, M. G., Rizal, R. M., \& Dozeno, J, "Rancang Bangun Mesin CNC 3-Axis Berbasis Mikrokontroler Arduino", 2019.

[7] Syaifudin, M., \& Syafri, S, "Pengaruh Kesalahan Dimensi terhadap Ketelitian Gerak Output Mesin Milling 3 Axes", 2017.

[8] Ihsan, R. Al, \& Arief, D. S, "Sistem Kendali Otomatis Pada Machine Vision Pengukur Volume Dan Berat", 2019.

[9] Zulfikar, Zoro, \& Syafri, "Proses Produksi Prototipe Mesin CNC Router 3-Axis", 2017.

[10] Rochim, Taufiq, "Spesifikasi, Metrologi \& Kontrol Kualitas Geometrik 1", Bandung: ITB, 2001.

[11] Rochim, Taufiq, "Spesifikasi, Metrologi \& Kontrol Kualitas Geometrik 2", Bandung: ITB, 2006

[12] Pratama, A. D, “Kontroler Lengan Robot Menggunakan Motor Servo Controller Robot Arm Using Servo Motor and Stepper Motor with Input 3 Axis", 2017.

[13] Latifa, U., \& Saputro, J. S, "Perancangan Robot Arm Gripper Berbasis Arduino Uno", 2018.

[14] Fitriani, Y., Pakpahan, R., \& Asyirri, A, "Perancangan Prototype Mesin CNC (Computer Numerically Controlled) Plotter 3 Axis 2D menggunakan Mikrokontroler Arduino Uno”, 2019.

[15] Fauzi, H, "Rancang Bangun Sistem Kontrol Mesin Laser Engraving Dengan Mikrokontroler Arduino", 2018. 